\title{
Papel do fiscal de contratos administrativos: uma análise sob a ótica gerencial na administração pública brasileira
}

Vinicius Carvalho Santos

Universidade Federal do Rio de Janeiro (UFRJ)

O modelo de gestão pública implementado pela reforma gerencial trouxe uma modificação na forma estática de administração de necessidades públicas em comparação a antigos modelos estruturais (patrimonialista e burocrático). Passou que a administração busque melhores formas de realizar uma mesma função, porém com vistas sempre ao aprimoramento organizacional. Dessa forma, a máquina pública deve buscar melhoramento nas formas de planejamento e controle a fim de que o contrato seja voltado à defesa dos interesses públicos, tendo como basilar que o principal objetivo do Estado é o atendimento dos serviços a ele demandados. Foi realizada uma pesquisa com vistas a mapear o papel do fiscal de contratos nesse novo Estado. A pesquisa tem caráter exploratório e bibliográfico. Por meio de análise documental, buscou-se destacar os problemas trazidos pelos antigos modelos estruturais e as formas pelas quais poderiam ser implementadas na função do fiscal de contratos, para que o mesmo aprimore o planejamento e o controle efetivado pelo Estado. Tendo na conclusão da pesquisa a constatação de que as atribuições do fiscal estão focadas na ótica do Estado Gerencial na prevenção de vícios e no papel de fornecedor de informações gerenciais para que o gestor tome decisões mais bem embasadas.

Palavras-chave: gestão de contratos - fiscalização, contrato público, reforma administrativa - Brasil

[Artigo recebido em 15 de janeiro de 2017. Aprovado em 22 de novembro de 2017.] 
Papel del fiscal de contratos administrativos: un analisis suboptimo gerencial en la administracion publica brasilera

El modelo de gestión pública implementada por la reforma de la gestión trajo un cambio en las necesidades de la Administración Pública forma estática en comparación con los modelos estructurales de edad (patrimoniales y burocráticos), al exigir que la Administración de buscar mejores maneras de lograr la misma función, pero siempre con el visto mejora de la organización. De este modo, la máquina debe buscar una mejora en los caminos de la planificación y control para garantizar que el contrato se guía a la defensa de los intereses públicos. Con la basilar que el principal objetivo del Estado está cumpliendo con los servicios que los son demandados. De este modo, mediante el análisis de documentos, que pone de relieve los problemas causados por los antiguos diseños estructurales y formas que podrían aplicarse en la función de los Fiscais del Contratos para que mejorar la planificación y el control efectuado por el Estado.

Palabras clave: gestión de contratos - fiscalización, contrato público, reforma administrativa - Brasil

\section{Role of the public contracts overseer: analysis from a managerial viewpoint in the brazilian public administration}

The Public Management model implemented by Managerial Reform has brought about a change Public Needs Management compared to old structural models (patrimonialist and bureaucratic) for requiring an administration to seek better ways to perform the same function, but always with a view to Organizational Improvement. In this way, in the context of public service provision in an indirect way, the Machine must seek improvement in the forms of planning and control so that the contract is based on the defense of public interests, having as basilar that the main objective of the State are services demanded to him. A survey was carried out to map the role of the Public Prosecutor in the New State. Thus, through documentary analysis, sought to highlight the problems brought by old models and forms that could be implemented in the function of the Fiscal of Contracts so that it improves the planning and control effected by the State in the process of acquisitions publics. - Brazil

Keywords: contract management - inspection, public contract, administrative reform 


\section{Introdução}

No último século, o Brasil passou por transformações gerenciais muito grandes em sua estrutura, pois, ao iniciar o século 20, o país apenas havia começado sua caminhada organizacional para a desconstrução dos modelos patrimonialistas trazidos pela monarquia, a qual havia sido extinta apenas 12 anos antes de 1901. Esse abandono se deu, entre outros motivos, devido a uma nova visão de sociedade, a qual - instigada pela pressão externa do resto do mundo - verificava que o governo se sustentava para atender às ânsias da população e, com isso, deveria ser algo de todos e não restrito a uma minoria.

Conforme o dicionário Priberam ${ }^{1}$ (2016): República vem do latim respública, de significação "a coisa pública", domínio do Estado. Em busca dessa representação de que os bens do Estado não poderiam mais estar nas mãos de particulares para seu bel-proveito, mas sim apenas para administração dos mesmos, fora realizada a Proclamação da República, em 1889.

Todavia, nos primeiros 50 anos, percebeu-se que esse favorecimento se mantinha, agora não mais nas mãos de uma família real, mas sim nas rédeas dos detentores de cargos políticos altos, os quais mantinham ainda políticas passadas do nepotismo e do empreguismo favorecido.

O Estado, para promover um desvio na estrutura histórica trazida pela Monarquia, adotou uma nova estrutura estatal, trazida por modelos já aplicados nos Estados Unidos e Europa, tendo como principais coadjuvantes Luís Simões e Maurício Nabuco. Tal modelo, denominado burocrático, priorizava um protecionismo da estrutura governamental frente ao patrimônio privado dos governantes, tendo como ônus o engessamento da máquina e uma preponderância dos procedimentos sobre os fins.

Em busca de uma melhoria nos procedimentos implementados por parte do modelo burocrático, foi promulgado o Decreto-lei no 200/67, o qual dispõe formas de organização administrativado Estado, propondo nesse segundo momento uma visão não somente de protecionismo do patrimônio público, mas com um enfoque mais voltado para a economicidade administrativa.

Nessa linhagem desenvolvimentista, foi promulgado o Regime Geral de Licitações e Contratos, Decreto-lei no 2.300/86, o qual previa, em seu art. 57 caput, o acompanhamento de fiscal específico para a execução do contrato, a fim de que o mesmo anotasse todas as ocorrências ocorridas na execução, bem como a previsão de que o mesmo determinasse a regularização de falhas e vícios constatados - decreto este que, no ano de 1993, foi transferido quase que em sua íntegra à Lei no 8.666 .

\footnotetext{
${ }^{1}$ http://www.priberam.pt/dlpo/republica
} 
Assim, conforme demonstrado pelo momento histórico, se fazia necessário um agente para a verificação de compatibilidade de execução do objeto contratado, sem se ater a critérios mais complexos, como alteração contratual, mudança de finalidades no decorrer do contrato, e questões acessórias fora da execução, a exemplo de regularidades trabalhistas, sociais, entre outras.

Devido à pressão internacional e interna do país, frente à realidade do início da década de 90, tendências gerencialistas mais intensas inundaram as pesquisas administrativas estatais, desembocando na transformação da Secretaria da Administração Federal em Ministério da Administração Federal e Reforma do Estado (MARE), órgão da administração direta responsável pela elaboração de planos de reforma administrativa.

Concretizando as políticas traçadas nos primeiros anos de governo do Presidente Fernando Henrique Cardoso, no ano de 1998 foi aprovada a Emenda Constitucional no 19/98, a qual, principalmente, inseriu no rol de princípios constitucionais o da eficiência, que roga, segundo Meirelles (2002):

[...] o que se impõe a todo o agente público de realizar suas atribuições com presteza, perfeição e rendimento profissional. É o mais moderno princípio da função administrativa, que já não se contenta em ser desempenhada apenas com legalidade, exigindo resultados positivos para o serviço público e satisfatório atendimento das necessidades da comunidade e de seus membros (MeIRELLES, 2002, p. 102)

Diante da perene construção de todo esse desenvolvimento do Estado Gerencialista que o Brasil tem hoje, percebe-se uma demanda cres cente de que a máquina pública cuide cada vez mais e melhor das atividades fins demandadas e busque formas alternativas de execução de atividades meio, porém efetuando controle, gerenciamento e coordenação do contratado, a fim de que o interesse público esteja resguardado em todas as fases da contratação.

A figura do fiscal neste atual momento histórico é impar na construção de um Estado Gerencial, voltado ao princípio da eficiência, já que a administração pública, conforme mencionado anteriormente, tende a um aumento significativo de pactuação de novos contratos, a fim de atender suas necesidades suplementares.

Não obstante, mesmo figura precípua na construção de aquisições públicas e execuções de serviços de qualidade, o papel do fiscal de contratos não tem sido muito trabalhado nas pesquisas científicas, voltadas à área de licitações e contratos, nem tampouco a execução de fiscalizações de contratos tem sido desempenhada com êxito. Pelo contrário, conforme Almeida (2009), caracterizou: “... não são raros 
os casos em que boas licitações e bons contratos são perdidos em seus fins devido a deficiências na fiscalização ou até mesmo na ausência desta" (ALMEIDA, 2009, p. 53).

Face ao exposto, esta pesquisa busca como objetivo principal analisar qual é o papel do fiscal de contratos, pautado sobre as premissas do novo Estado brasileiro, nos processos de aquisições.

Nesse diapasão, para que esta pesquisa alcance seu fim, é necessário identificar: quais deficiências impedem os mesmos de atingir resultados eficientes, quais vícios trazidos pelos antigos modelos estruturais impedem uma fiscalização contratual gerencial e quais demandas são exigíveis dos fiscais de contrato a fim de que os mesmos possam propiciar o maior proveito possível de suas competências no procedimento de contratações públicas.

\section{Procedimentos metodológicos}

Foi realizada uma pesquisa histórica dos diferentes tipos de estrutura organizacional da maquina pública brasileira, correlacionando as mesmas com as formas de execução - direta ou indireta - de serviços públicos, bem como o posicionamento social histórico das formas de controle, a fim de se identificar as visões históricas de cada momento sobre os controles administrativos.

Em seguida, foi realizado um levantamento conceitual dos principais procedimentos e atores estruturais da administração pública brasileira na sua parte de prestação de serviços de maneira indireta. Logo após, foi consultada uma série de artigos científicos, voltados à área de controle público, e licitações e contratos, e publicações jurisprudenciais de órgãos de controle externo e do Superior Tribunal de Justiça (STJ). Todos esses procedimentos, visando extrair os problemas que impedem que a Fiscalização Contratual seja exercida em sua plenitude, assim como o motivo ensejador da existência de tantos vícios nos contratos administrativos (na fase de planejamento e na executória) e qual é a correlação entre a existência dos mesmos e os modelos antigos de estrutura governamental.

\section{Referencial Teórico/Doutrinário}

\section{Construção histórica dos modelos}

O Brasil viveu durante séculos sob o controle da coroa real de Portugal, a qual adotava o regime de uma estrutura monarquica tradicional patrimonialista, em que era quase negligenciada a distinção entre patrimônio público e privado. Esse formato permitia a manutenção do poder em um único nicho social e de benefícios para um seleto grupo social. 
Em meados da década de 30, a fim de possibilitar o rompimento da configuração governamental trazida pela monarquia, o governo teve que rever o modelo implantado nos primeiros anos de Republica, e com isso deu lugar à administração burocrática clássica, a qual foi implantada nos principais países europeus no final do século 19; nos Estados Unidos, no começo do século 20; no Brasil, em 1936. É a burocracia que Weber descreveu, baseada no princípio do mérito profissional (BRESSER-PEREIRA, 1996, p. 3).

Para Bresser-Pereira (1996, p. 4) "este modelo veio para promover uma clara distinção entre o público e o privado, bem como para promover a separação entre o político e o administrador público, com todo esse modelo, baseado na visão racional-legal". Na primeira reforma do século em comento já se depreende uma necessidade precípua de implantação de medidas de controle a fim de coibir ações particulares voltadas a interesses próprios; com isso já se levanta a exigibilidade de Agentes Públicos responsáveis com o controle das verbas estatais, as quais viviam sendo regularmente usurpadas.

A partir de 1938, via-se um país em busca de um delineamento administrativo mais voltado ao pensamento gerencialista, já que no mesmo ano fora criada a primeira autarquia brasileira e com isso já nascia a ideia de que nem todos os serviços públicos necessitariam de ser realizados centralizadamente, tendo, nesse ato, o início da reflexão de que o Estado não necessariamente deveria realizar todas as ações executivas.

Em 1967, foi promulgado o Decreto-lei no 200/67 o qual marcava o reconhecimento de que a administração direta não havia sido capaz de responder com agilidade, flexibilidade, presteza e criatividade às demandas e pressões de um Estado que se decidira desenvolvimentista. A esse entendimento está subjacente a ideia de que a executoriedade de serviços pela administração direta havia falhado ( BERTERo, 1985 ). Nessa interpretação, reafirma-se a ideia de que a administração necessitaria descentralizar para responder aos anseios públicos.

Neste diapasão, Ferraz (1997) assevera que o Decreto em monta implementou a reforma administrativa com seus postulados de planejamento, coordenção, supervisão, delegação de competência e controle específicos. Em face disso, uma das maiores soluções trazidas pela legislação foi a do artigo 10, §7으, o qual preceitua que a administração deveria desobrigar-se de tarefas executivas, recorrendo, sempre que possível, à execução indireta mediante contrato, devendose ater iminentemente ao controle e à supervisão da prestação do serviço - art. 10, $\S 6$. Nesse texto legal nasce o instituto da terceirização, o qual, em certos pontos, auxiliou na redução da máquina estatal, no primeiro momento. 
Após uma crise estrutural pela qual o país passou nos anos de ditadura militar, em face à coincidência desse mesmo período com a falência do modelo burocrático, o qual começou a indicar que não atendia mais às demandas nacionais. Tudo isso eclodiu em um momento social inflacionária desfavorável. Em resposta, foi iniciada, no primeiro mandato do Presidente Fernando Henrique Cardoso (19951998), uma reestruturação na gestão pública, em prol de um reestabelecimento do modelo estrutural.

Conforme textualizado por Bresser-Pereira, em 2007, o principal mentor dessa reestruturação:

[...] era uma imposição histórica para o Brasil, como para todos os demais países que havia nos cinqüenta anos anteriores montado um Estado do Bem Estar. O grande crescimento que o aparelho do Estado se impusera para que pudesse garantir os direitos sociais, exigiam que o fornecimento dos respectivos serviços de educação, saúde, previdência e assistência social fosse realizado com eficiência. Esta eficiência tornava-se, inclusive, uma condição de legitimidade do próprio Estado e de seus governantes (BRESSERPEREIRA, 2007, p. 5).

Conforme citação do Ministro, essa mudança estrutural se baseava precipuamente em uma transformação de visão dos agentes públicos para a importância da forma pela qual o Estado estava sendo gerido, formalismo preponderante, e como deveria ser, segundo tendências organizacionais internacionais, primazia nos fins mas também com controle dos meios. Para o mesmo, essa mudança se baseava em frentes, a saber:

a. orientação da ação do Estado para o cidadão-usuário ou cidadão-cliente;

b. ênfase no controle dos resultados através dos contratos de gestão (ao invés de controle dos procedimentos);

c. fortalecimento e aumento da autonomia da burocracia estatal, organizada em carreiras ou "corpos" de Estado, e valorização do seu trabalho técnico e político de participar, juntamente com os políticos e a sociedade, da formulação e gestão das políticas públicas;

d. separação entre as secretarias formuladoras de políticas públicas, de caráter centralizado, e as unidades descentralizadas, executoras dessas mesmas políticas;

e. distinção de dois tipos de unidades descentralizadas: as agências executivas, que realizam atividades exclusivas de Estado, por definição monopolista, e os serviços sociais e científicos de caráter competitivo, em que o poder de Estado não está envolvido; 
f. transferência para o setor público não-estatal dos serviços sociais e científicos competitivos;

g. adoção cumulativa, para controlar as unidades descentralizadas, dos mecanismos de controle social direto, do contrato de gestão em que os indicadores de desempenho sejam claramente definidos e os resultados medidos, e da formação de quase-mercados em que ocorre a competição administrada;

h. terceirização das atividades auxiliares ou de apoio, que passam a ser licitadas competitivamente no mercado

Para fins da análise aqui proposta, levanta-se como marcante para o início de uma nova forma de gerenciamento, não só contratual, mas também de gestão de aquisições do Estado, os itens " $b$ " e " $h$ " , já que os mesmos realçam uma necessidade de reanalisar como estão sendo geridas as fiscalizações contratuais e como os contratos estão sendo montados, a fim de que possam atender realmente a demanda estatal.

\section{Fiscalização Contratual - Uma breve introdução à compreensão de sua atuação: conceitos basilares.}

Carvalho Filho (2002, p. 257) conceitua serviço público como sendo toda atividade prestada pelo Estado ou por seus delegados, basicamente sob regime de direito público, com vistas à satisfação de necessidades essenciais e secundárias da coletividade. Em complemento, Meirelles (2001, p. 289) descreve serviço público como sendo todo aquele prestado pela administração ou por seus delegados, sob normas e controle estatais, para satisfazer necessidades essenciais ou secundárias da coletividade ou simples conveniência do Estado.

Consolida-se, das conceituações acima explanadas, que serviço público se define pela precipuidade do atendimento das necessidades da coletividade, sempre visando à conveniência e à oportunidade pública, o qual poderá ser prestado de forma direta, pela máquina estatal, ou por terceiros; estes sob normas públicas e controle da máquina estatal. Tal visão adveio do desenvolvimento estatal trazido pelo modelo que se denomina hoje como Gerencial. Esta forma de organização se baseia na premissa - quanto a serviços públicos - de que os mesmos nem sempre são prestados da maneira mais eficiente, diretamente pelo poder público, em razão do Estado não ter estrutura suficiente para realizar todas as funções que são demandadas.

Para Aragão (2007), parafaseando Egon Bockmann Moreira, não se atribui importância à titularidade do serviço público, mas sim à responsabilidade do Estado sobre a atividade, em virtude de sua obrigação de prestar o serviço público. 
Nessa linhagem retira-se a conceituação de terceirização para Silva (apud RAMos, 2001, p. 50):

“[...] a transferência de atividades para fornecedores especializados, detentores de tecnologia própria e moderna, que tenham esta atividade terceirizada como atividade-fim, liberando a tomadora para concentrar seus esforços gerenciais em seu negócio principal, preservando e evoluindo em qualidade e produtividade, reduzindo custos e gerando competitividade."

A Constituição Federal de 1988 prevê em seu art. 37, XXI, que, exceto nos casos específicos em lei, os quais se baseiam em atividade-fim do Estado, os serviços deverão ser contratados mediante processo de licitação pública que assegure igualdade de condições entre todos os concorrentes. Assevera assim a Carta Magna que, sob o princípio norteador do interesse público, a finalidade pública, sejam contratados terceiros, para a execução de atividades-meio, não-finalísticas.

Contratos administrativos, segundo Di Pietro (2004, p. 240 ), são os ajustes que a administração, nessa qualidade, celebra com pessoas físicas ou jurídicas, públicas ou privadas, para a consecução de fins públicos, segundo o regime jurídico de direito público. Registra-se, ainda, que esse acordo de vontades de que o poder público se utiliza para atingir seu objetivo organizacional detém normas específicas, e com isso se distingue na forma de elaboração e execução, já que prevalece o princípio da primazia do interesse público sobre o privado, possibilitando a flexibilização de princípios comuns de regime contratual privado como o exceptio non adimpleti contractus $^{2}$ (exceção ao contrato não cumprido), pelo qual no direito público, mesmo com a ausência de pagamentos por parte da administração pública, por período não superior a 90 dias, o contratado não poderá suspender a prestação do serviço, sob pena de sanção aplicável ao mesmo.

Outrossim, mesmo a atividade-meio sendo prestada por fornecedores privados especializados, estes, por executarem serviço público, devem estar regulados e controlados por normas de direito público e conforme prevê o Regime Geral de Licitações e Contratos - regulamentado pela Lei no 8.666/93 -; no art. 58, III, há a necessidade de fiscalização da execução do contrato, bem como apresentase no art. 67 da mesma lei a necessidade de indicação de um representante da administração especialmente designado para o acompanhamento e fiscalização da execução do contrato.

\footnotetext{
${ }^{2}$ Trata-se de ferramenta, através da qual, um dos polos do contrato se escusa de adimplir sua obrigação enquanto o outro não executar a que lhe cabe.
} 
Almeida (2009, p. 54) pontua a definição de fiscalização do contrato de maneira simplória, como sendo a parcela de gestão contratual que focaliza a exigência do cumprimento contratual por parte da contratada. Todavia, essa visão se restrige à ação de fiscalização contratual de antigos modelos estruturais, os quais previam somente a necessidade da fiscalização sem vê-la como procedimento que deverá andar juntamente com o acompanhamento do contrato e dos elementos que o influenciam, já que essa última ação coloca o Poder Público em posição estratégica não só de frente ao contratado, mas também à frente de possíveis modificações no ambiente macro-econômico que englobam o respectivo contrato.

O fiscal contratual, conforme aponta Almeida (2009, p. 54), é visto nas relações de mercado como a mão forte do dirigente do órgao ou entidade e o mais importante agente da administração no que se refere ao contrato que supervisiona. Todavia, essa visão demostra-se limitada, não contemplando os recentes desenvolvimentos do princípio da eficiência pública, o qual é objeto de desenvolvimento contínuo desde 1998. Com isso o fiscal não pode ser visto somente como uma mão de "força" na execução contratual, mas também como mão estratégica do órgão, no apontamento de melhores soluções para problemas que surgem no decorrer da gestão contratual. Assim, esse braço estratégico deve colocar-se junto ao contratado para buscar melhores formas de solução, já que nem o fiscal nem a empresa responsável pela execução do contrato, via de regra, buscam um fim distinto de uma melhor execução contratual. A executante sabe muito bem que, além dos problemas de imagem que poderá ter junto ao mercado, com uma má atuação na execução, haverá problemas jurídicos, podendo até ser, em última instância, inabilitada para contratar junto ao Poder Público.

Contudo, mesmo com a previsão legal de punibilidade para a empresa contratada quando a mesma realiza práticas ilegais, conforme prevê Seção II da Lei no 8.666/93, há a necessidade de estabelecimento de responsabilidades e competências para os agentes públicos responsáveis pela gestão dos recursos públicos nesses contratos, a fim de prevenir que a atuação dos mesmos vise a objetivos privados, sob pena de a máquina pública retroagir aos vícios de antigas construções patrimonialistas, nas quais a distinção entre o patrimônio público e o privado era quase imperceptível.

Segundo Meirelles (2002, p. 119), entende-se por competência administrativa o poder atribuído ao agente da administração para o desempenho específico de suas funções. Em complemento, Tácito (1987, p. 97 ) assevera: "não é competente quem quer, mas quem pode segundo norma de direito". Conforme retira-se da citação acima, competência se baseia na limitação de atribuição de funções dentro do rol de agentes públicos possíveis de ação - esta limitação sempre estabelecida mediante lei. Tal instituto é necessário como meio de controle dos agentes públicos 
para que cada qual seja responsabilizado não somente de maneira inteiramente ligada aos atributos estabelecidos segundo a lei, mas, também, para ciência de suas atribuições quanto à boa prestação e desenvolvimento das mesmas, segundo os princípios da norteadores da administração pública, tendo em primazia os da eficiência administrativa e legalidade.

O fiscal de contrato é um servidor designado, geralmente por portaria, que fica vinculado à responsabilidade do acompanhamento da execução do contrato, a fim de que seja assegurada a prestação do serviço, de acordo com o contrato, o qual tem como finalidade uma necessidade que ensejou a contratação. Em razão da finalidade ser o principal atributo responsável pela existência (ou não) do contrato, a mesma deve ser tratada como uma das mais importantes partes integrantes do contrato e o responsável designado para essa fiscalização deverá ter noção da amplitude a qual abarca esta necessidade explanada no termo de referência e/ou projeto básico.

A atuação dos agentes públicos, sobretudo no que se refere aos fiscais de contrato, foi redesenhada e repensada a partir do Princípio da Eficiência, o qual prevê, segundo Di Pietro:

...o princípio apresenta-se sob dois aspectos, podendo tanto ser considerado em relação à forma de atuação do agente público, do qual se espera o melhor desempenho possível de suas atuações e atribuições, para lograr os melhores resultados, como também em relação ao modo racional de se organizar, estruturar, disciplinar a administração pública, e também com o intuito de alcance de resultados na prestação do serviço público... (DI PIETRO, 2002)

Conforme se retira dos aspectos acima explanados, a Emenda à Constituição no $19 / 98^{3}$, que alterou de maneira direta o funcionamento da administração pública, deverá ser tratada como tal. Em primeira análise, modifica a forma pela qual o agente público atua, não mais somente de maneira a atender à legalidade e aos procedimentos burocráticos tradicionais, mas, também, agora, atento ao atingimento de uma eficácia de maneira cada vez mais satisfatória. Em segunda ordem, além da alteração trazer modificações quanto à eficácia dos objetivos da administração pública, propõe uma visão mais racional da revisão dos procedimentos trazidos pela Teoria Burocrática de Weber.

\footnotetext{
${ }^{3}$ Essa emenda marcou a administração pública por inserir no rol de princípios constitucionais o da eficiência na administração.
} 
Fiscal de contratos e seu redesenho funcional, segundo o novo Estado ao qual se arcabouça desde meados de 1998:

Na década de 90, o Estado, conforme visto anteriormente, buscou novas formas de reestruturação, a qual, em essência, ainda se apresentava como burocrática clássica e, com isso, não permitia que a máquina visse reestruturações de acordo com modelos internacionais já implementados na nova visão de Estado, segundo uma ótica Gerencial. Ainda assim, mesmo tendo um alto nível de burocracia justificada por si só, sofria com favoritismo em contratações públicas (conforme verificado nos Acórdãos do Tribunal de Contas da União 395/95, 489/95, 402/95, 576/93, 486/93, 474/93, dentre vários outros retirados do site ${ }^{4}$ daquele Órgão de Controle).

Em 1998 tiveram dois pilares que marcaram a construção do novo modelo:

- promulgação da eficiência como princípio constitucional, proposta esta que busca melhores formas de execução dos atos administrativos, com vistas à melhoria contínua das formas de prestação de serviços públicos;

- crescimento da participação da tecnologia da informação na gestão pública, progresso este que permitiu avanços significativos nos controles implementados pela administração.

Diante da crescente atuação de agentes públicos de controle mais voltados ao alcance da finalidade pública, sob o novo prisma gerencial, exige-se que os fiscais de contratos se ponham não somente sob a ótica de punibilidade do contratado, ou melhor, de carrasco do contrato, mas sim com um posicionamento de resguardo do interesse público e do equilíbrio econômico e financeiro do contrato, manutenindo a balança de direitos e obrigações pactuados.

Ao atuar como agente viabilizador do fiel da balança no contrato, o fiscal assegura que nem o contratado irá executar o objeto do contrato de forma leviana, no caso da administração valer-se da preponderância do interesse público sobre o privado de forma desmedida, nem os administradores da Máquina Estatal irão abrir mão de interesses públicos assegurados, visando a proveitos particulares.

Nessa linha, assevera o Tribunal de Contas da União (TCU) em Acórdão no $963 / 2010^{5}$, no item 8.8 , sub item 27 :

8.8. Do exposto, podemos ratificar que está ocorrendo desequilíbrio na equação econômico financeira pactuada, que se expressa pela equivalência entre os encargos da contratada e a retribuição da CAIXA, inicialmente fixados.

\footnotetext{
${ }^{4}$ https://contas.tcu.gov.br/juris/Web/Juris/ConsultarTextual2/Jurisprudencia.faces

${ }^{5}$ BRASIL. Tribunal de Contas da União. Acórdão 963/2010. Relator: Benjamin Zymler. Publicado. Disponível em: https://contas.tcu.gov.br/juris/Web/Juris/ConsultarTextual2/Jurisprudencia.faces.
} 
Ressaltamos que não é lícito à Administração Pública locupletar-se à custa do particular.

(...)

27. Quanto à vedação ao reajuste prevista no contrato firmado com a Tecnocoop, cabe ressaltar que a jurisprudência desta Corte de Contas é no sentido de que deverá assegurar-se ao interessado o direito a esse instrumento de reequilíbrio econômico-financeiro do contrato, ainda que não esteja previsto contratualmente, uma vez que a Lei n. 8.666/93 (arts. 5o, $\S 1$, e $40, \mathrm{XI}$ ) garante aos contratados a correção dos preços a fim de que lhes preservem o valor. (Grifo inserido)

No caso em comento, a Corte máxima de Contas da União se posicionou quanto à preponderância da manutenção do equilíbrio contratual sobre formalismos burocráticos, os quais, devido a vícios constantes desde a fase de elaboração da minuta do contrato, já eram verificados, e com isso o particular não poderia ser onerado de maneira a provocar um desequilíbrio na equação econômico financeira pactuada. Aqui nota-se a preocupação da administração sob o prisma de cuidado com a relação estabelecida anteriormente, mesmo que essa exija um maior desembolso financeiro ao erário.

Em mesmo raciocínio, o próprio TCU reafirma, em posicionamento mais recente, a visão exposta acima, ressaltando, desta vez, a necessidade de averiguação de possível responsabilização do agente que agiu de maneira inadequada. O Acórdão no 3.289/20116 , item 32, prevê:

32. Ressalto, também, que ausência de tempestiva formalização de alteração do modo de reajuste original não pode impedir o reconhecimento posterior da necessidade de que se houvesse procedido à referida modificação da fórmula de reajuste praticada, ainda que disso resulte o reconhecimento de grave infração a norma legal, imputável àquele ex-Prefeito'.(Grifo inserido)

Nesse último caso, demonstra-se o posicionamento daquela corte no sentido de que a relação contratual não pode ser descompensada em seu equilíbrio contratual de direitos, em razão de omissão - por dolo ou culpa - de agente responsável por promover a materialização do reconhecimento de necessidade de um possível equilíbrio, que o contrato exigiria. Nessa seara adentra a figura do fiscal de contratos, promovendo a segurança de que o gestor seja provocado tempestivamente para a realização de reajustes, repactuações e revisões e, quando cabível, que o agente preste informações tempestivas ao contratado, a fim de proteger a relação jurídica pactuada anteriormente.

\footnotetext{
${ }^{6}$ BRASIL. Tribunal de Contas da União. Acórdão 3.289/2011. Relator: José Jorge. Publicado. Disponível em: https:// contas.tcu.gov.br/juris/Web/Juris/ConsultarTextual2/Jurisprudencia.faces.
} 
Não obstante, o mesmo Tribunal que prevê uma manutenção do equilíbrio econômico e financeiro do contrato se resguarda com o posicionamento de que as concessões de direitos ao particular, quando infrinjam direitos da administração previstos anteriormente, deverão ser punidas a fim de resguardar os direitos da máquina, conforme demostra-se com o julgado que ensejou a edição do Acórdão no 2.714/20157, registrado no Informativo de Licitações e Contratos do TCU em edição 265:

...o atraso na conclusão das obras expõe a população local aos riscos de novas enchentes e catástrofes naturais, como a que foi verificada em janeiro/2011... quando a Administração concorre para o descumprimento dos prazos acordados, a apuração de responsabilidades dos gestores é cabível, principalmente quando a dilação for consequência de negligência, imperícia ou imprudência dos gestores. De outra forma, nos atrasos advindos da incapacidade ou mora da contratada, o órgão contratante tem o dever de adotar as medidas cabíveis para aplicar as multas contratuais e demais penalidades previstas em lei. (Grifo incluído)

No caso acima, verifica-se a desídia por parte dos gestores e fiscais contratuais na condução do processo de execução, ao permitir continuidade na execução do objeto do contrato, sem advertências, mesmo tendo sido registrados atrasos, sob embasamento da falta de controle das inexecuções do cronograma físicofinanceiro aprovado inicialmente. Nesse diapasão, o órgão de controle, de maneira ímpar, pontua que qualquer que for a desídia por parte do órgão gestor, houve uma responsabilização da gestão contratual em permitir que a administração se expusesse a riscos previstos, porém com repercussões incalculáveis, já que, caso a responsabilidade fosse imputada à empresa executante, esta deveria ter sido punida, com as sanções previstas em contrato, e caso fosse imputada à administração e seus administradores devido à imprudência, imperícia ou outras preocupações que os mesmos deveriam ter na qualidade de homem médio $^{8}$, a responsabilização deveria ser apurada e, após a análise subjetiva, punida.

Verifica-se, nos julgados acima expostos, que a preocupação da Máquina Pública vem crescendo no sentido de que os administradores públicos, além da responsabilização pela prática de atos ilegais, ou ilegítimos, por dolo, também devem ser punidos por se omitirem em situações graves que possam causar prejuízo à finalidade do Estado.

\footnotetext{
${ }^{7}$ BRASIL. Tribunal de Contas da União. Acórdão 2.714/2015. Relator: Benjamin Zymler. Publicado. Disponível em: https://contas.tcu.gov.br/juris/Web/Juris/ConsultarTextual2/Jurisprudencia.faces.

${ }^{8}$ Homem Médio segundo a TC 17.825/2009-2 do Tribunal de Contas da União é pessoa que contém uma compreensão mediana, ou seja, alguém prudente e diligente.
} 
Nessa seara, reconhece a responsabilidade direta dos fiscais contratuais na necessidade de exposição de informações que produzam conhecimento, para que, conforme afirma Braga (1996, p. 16), a informação reduza o nível de incerteza no processo de tomada de decisão, por parte do órgão gestor. Nessa linha intelectiva, depreende-se dos acórdãos transcritos acima que a ocorrência dessas falhas por parte dos fiscais contratuais e em consequência dos gestores se deram devido a um não aproveitamento por parte dos mesmos de tecnologias da informação, com a finalidade de promover controles necessários à boa e otimizada gestão da execução contratual. A fim de implementar esses controles, é necessário um planejamento não somente da contratação, mas também da fiscalização, a qual será implementada caso a caso e, para isso, é necessária a construção de um ambiente organizacional estratégico, que, conforme expõem Valentim (2010, p. 14) se baseia em: “...elaboração de políticas, planos e planejamentos, à tomada de decisão estratégica e ao estabelecimento de estratégias de ação de médio e longo prazo".

A fim de concluir a ideia trazida, assevera Amaral (2016, p. 7) quanto à condição básica para uma boa operacionalidade contratual:

Um bom contrato não é aquele em que uma das partes subjuga a outra à sua vontade. Também não é o em que as partes, felizes e risonhas, caminham em busca de um objetivo comum. Um bom contrato é o que não só bem celebrado, mas, sobretudo bem administrado conduz as partes a satisfazerem seus respectivos interesses, apesar de serem estes divergentes (AMARAL, 2016, p. 7).

O trecho supratranscrito apresenta uma visão quanto à administração que facilitará muito a forma de gestão por parte dos órgãos públicos e dos fiscais contratuais, já que, se os mesmos compreenderem que a finalidade do Estado é atender as demandas da população e a finalidade das empresas privadas é gerar lucro, poderão equilibrar essas necessidades, sem entender que é ilegal ou ilegítimo que o privado tenha a prerrogativa do lucro, já que esta garante a contínua manutenção de um mercado sempre aberto à negociação com o poder público.

Caso a administração utilize de suas supremacias legais para agir de forma irrazoável na gestão contratual, poderá ocorrer em uma próxima contratação uma perda de credibilidade da administração para com o mercado, e em longo prazo poderá ocorrer um efeito em cadeia de reducionismo mercadológico que poderá segregar o campo de pesquisa de preços em futuros contratos. 


\section{Fiscalização contratual competente e sua atuação tempestiva}

\section{Fiscal contratual e as competências profissionais exigíveis}

Segundo Di Pietro (2003 ) "a competência é um atributo ou um requisito de validade do sujeito". Esse conceito advém de uma ótica jurídica, a qual busca a responsabilidade de um agente pela prática de um ato específico. Todavia, não menos nem mais importante é a visão administrativa trazida por Chiavenato (2003, p. 4), o qual entende que competências são "qualidades de quem é capaz de analisar uma situação, apresentar soluções e resolver assuntos ou problemas". Em desenvolvimento da conceituação exposta, Carbone, Brandão e Leite (2005) propõem que competências humanas ou gerenciais são combinações sinérgicas de conhecimentos, habilidades e atitudes, expressas pelo desempenho profissional dentro de determinado contexto organizacional, que agregam valor a pessoas e organizações.

Trazendo a conceituação para o mundo da fiscalização contratual, o agente responsável pela mesma deverá ter conhecimentos aprofundados na área de licitações e contratos, bem como conhecimentos técnicos específicos na área que abarca o objeto da contratação em monta, sob pena de ficar à mercê da contratada e de possíveis responsabilizações futuras em procedimentos de prestação de contas, por má gestão contratual. Visando à segurança de que o fiscal terá, ao menos, os conhecimentos técnicos voltados à área do objeto, são designados geralmente para a fiscalização pessoas que façam parte do grupo ao qual será usuário dos serviços e produtos contratados. Todavia, conforme demonstra pesquisa realizada em duas instituições federais de ensino ${ }^{10}$, os usuários desconhecem a necessidade de treinamentos na área ou em temas relacionados a licitações e contratos, e muito menos possuem treinamentos constantes voltados ao tema ${ }^{11}$.

Além de conhecimentos, é exigível que o fiscal contratual tenha certas habilidades específicas. Para efeito desta pesquisa, toma-se como base o entendimento de Chiavenato (2003), de que habilidade é a capacidade de transformar conhecimento em ação e que resulta em um desempenho esperado. A fim de caracterizar o efetivo cumprimento de mais um requisito na construção do agente competente, deve-se

\footnotetext{
${ }^{9}$ I Seminário de Direito Administrativo - TCMSP “Processo Administrativo", ocorrido entre 29 de setembro e 3 de outubro de 2003.

${ }^{10}$ Pesquisa apresentada no artigo: Análise de correspondência aplicada a preposições sobre a eficiência e eficácia do processo de compras públicas a partir da percepção de diferentes atores envolvidos. Formado por Isaac Gezer Silva De Oliveira.

11 Além de pesquisa aponta-se também trecho do Relatório de Auditoria do TCU presente no processo: 026.387/2015-8: "Tais entrevistas corroboram o entendimento de que o IFMG não adota as práticas relativas à capacitação dos ocupantes de funções-chave da área de gestão das aquisições".
} 
perceber que esta - a habilidade - tem uma correlação direta com o conhecimento, já que, conforme exposto acima, só há de se considerar um ser habilidoso segundo os conhecimentos adquiridos por ele e postos em prática. Assim sendo, como se verificou em pesquisa publicada, os conhecimentos específicos de licitações e contratos não são de domínio e, consequentemente, as práticas não estão em consonância com os recentes desenvolvimentos das práticas administrativas públicas, reverberando em maus resultados na gestão contratual.

Já a atitude, segundo Chiavenato (2003, p. 5), "representa o estilo pessoal de fazer as coisas acontecerem, a maneira de liderar, de motivar, de comunicar e de levar as coisas para a frente". O fiscal de contratos, por ser a mão operacional do órgão no levantamento de informações e na tomada de decisões operacionais, deverá ter, além de posturas condizentes com um representante da administração, também a expertise ${ }^{12}$ necessária a um julgamento de mérito subjetivo, a qual poderá somente ser aprimorada na prática contínua de atos correlatos voltados à prática da fiscalização contratual. Esse requisito se parte em duas facetas: o foco postural e o de experiência passadas. Quanto ao primeiro, conforme concluiu Almeida (2009), "a atribuição de fiscal de contrato é, antes de tudo, uma questão de postura", isso porque o agente deve estar pronto para tomar medidas necessárias - em todo tempo do contrato - para proteger o interesse público. Experiências passadas auxiliam no desenvolvimento da execução contratual pelo fato do fiscal já ter em mente uma matriz SWOT ${ }^{13}$ do ambiente que rodeia aquela execução contratual, em linhas gerais.

\section{Planejamento da Contratação - um momento estratégico sob a ótica de construção do processo de aquisição pública}

Planejar, segundo conceituação retirada do dicionário Priberam(2016) ${ }^{14}$, significa "definir antecipadamente um conjunto de ações ou intenções, ter algo como intenção". Diante dessa ótica, verifica-se que a ação de planejar permite que seja delineado um foco ou objetivo ao qual se quer chegar, bem como uma previsão das ações que serão adotadas a fim de chegar ao objetivo estabelecido. Em complemento à definição acima trazida, apresenta-se um posicionamento da Corte de Contas da União:

O processo de planejamento da contratação destina-se a viabilizar a seleção da alternativa de contratação mais vantajosa para a Administração, em subordinação

\footnotetext{
${ }^{12}$ Segundo o dicionário Priberam(2016): Expertise, se origina da palavra francesa èquecèrtizel que representa avaliação - por peritos.

${ }^{13}$ Matriz SWOT se trata de uma ferramenta estrutural da administração, que possui como principal finalidade avaliar os ambientes internos e externos, formulando estratégias de negócios.

${ }^{14}$ https://www.priberam.pt/dlpo/planejar
} 
aos princípios da motivação, da isonomia, da legalidade, da impessoalidade, da moralidade, da igualdade, da publicidade, da eficiência, da probidade administrativa, da vinculação ao instrumento convocatório, do julgamento objetivo, e às diretrizes de ampliação da competitividade e de garantia do atendimento do interesse público, da finalidade e da segurança da contratação (TCU, 2007) $)^{15}$.

No trecho supracitado, apresenta-se o planejamento na visão das contratações públicas e as finalidades às quais buscam alcançar na realização da ação de planejar antecipadamente - seja para contratação de serviço/obra e/ou para aquisição de produtos. Nesse diapasão, salienta-se que todo processo de contratação, conforme explanado anteriormente, deverá ter como finalidade o atendimento das necessidades públicas. Com isso, mesmo tendo todo o rol acima explanado de finalidades que se buscam alcançar no planejamento, a administração pública deverá ter em mente que o principal é o atendimento às necessidades da população, objetivo elementar de toda a contratação realizada pelo Poder Público.

Conforme retrata Mendes (2012, p. 25), “(...) o planejamento da contratação deve passar de coadjuvante a ator principal, e a licitação, de atriz principal a coadjuvante" (grifo do original). A fase de planejamento nas contratações deverá ser revista no processo de importância, já que a mesma é tida como uma das fases mais "desimportantes" sob a visão dos administradores públicos, em consoante explanou Amaral (2010):

Na prática, o planejamento de uma contratação (...) termina sendo ineficiente pela preocupação que se tem de fazê-lo rápido e ágil. Não se costuma 'perder' tempo com o planejamento. Com isso, causa-se prejuízo que uma licitação rápida e ágil não tem o dom de reparar. (grifo inserido) (AMARAL, 2010)

$\mathrm{Na}$ listagem de princípios constitucionais, não esta previsto o princípio da precipuidade da aceleração processual em procedimentos de contratação da administração pública. Todavia, os gestores públicos, por motivos diversos subjetivos - falta de tempo, pelo não acinamento do início do processo de modo tempestivo, necessidade de crecimento institucional do nome do gestor dentro do órgão sob basilares de uma premeditada correlação entre rapidez e eficiência, entre outros motivos - busca-se uma aceleração de procedimentos, mesmo que esses custem uma perda na qualidade do planejamento inicial que será realizado. Isso acaba acarretando uma deformação na etapa inicial do procedimento aquisitivo.

\footnotetext{
15 http://portal2.tcu.gov.br/portal/page/portal/ticontrole/legislacao/repositorio_contratacao_ti/001.002.050. html
} 
A figura do fiscal de contratos, nessa seara, se apresenta de importância ímpar no processo de construção do planejamento da contratação, já que o mesmo tem contribuições executórias, as quais agentes que apenas efetivam a especificação de itens necessários a uma execução do objeto (Projetistas), em via de regra normal, não têm. Além da significância da presença do fiscal no processo, antes mesmo de ser pactuado o contrato, é importante sua contribuição técnica no planejamento. O fiscal, por ter ciência dos motivos ensejadores das especificações tratadas, buscará na execução não somente o cumprimento da mesma, mas também terá a preocupação de atender à finalidade específica que fez nascer a especificação em comento. Nesse sentido explana Barral (2016, p.12):

... a formalizaçao da designação do fiscal deveria ocorrer na fase de preparo do certame licitatório, de modo que a experiência angarida pelo Fiscal em contratações anteriores fosse aproveitada na nova contratação, através da melhoria da redação do contrato e do edital, na correção da estimativa do objeto, nas rotinas de execução...(BARRAL, 2016)

A nomeação do agente (ou conjunto de agentes) que será responsável pela execução do contrato - antes da assinatura do instrumento contratual - auxilia, também, na minimização de erros trazidos por incompatibilidade entre o projeto básico e a planilha orçamentária levada à licitação, já que essa prática é comum em procedimentos de contratação, conforme artigo da Universidade Estadual de Londrina, em estudo apresentado por Nascimento e Tomaél (2012, p. 93):

... encontrou-se como a informação que motivou a maior parte de aditamentos para alteração de planilha de serviços foi o fato de existir itens não contemplados na planilha básica licitada; mas, constantes no projeto e necessários para a devida utilização da construção (NASCIMENTO; TOMAÉL, 2012, p. 93).

Conforme apresenta o trecho do artigo, essas faltas de controles quanto a incompatibilidades, as quais seriam reduzidas em uma revisão realizada por parte do fiscal, acabam por trazer prejuízos à administração, não somente financeiros, mas também temporais, por - dependendo da alteração - demandar mais tempo na execução em comparação à previsão anteriormente mensurada.

\section{Execução contratual - a foz contratual dos vicíos constantes no processo de contratação pública}

A execução contratual é a fase na qual a maioria dos problemas, vícios e incongruências desembocam - independente da fase que os originou - já que é a fase objetivo de toda a contratação. Trata-se do momento em que, na prática, 
se constrói de maneira física o objeto contratual. Contribuindo para essa pratica equivocada - de construção de um processo vicioso pela importância maior dada aos procedimentos do que à finalidade da contratação - o fiscal de contratos é designado logo após assinado o contrato e, com isso, é responsabilizado por toda a eficiência executória de um procedimento já abarrotado de vícios em seu escopo básico, mesmo não tendo montado o processo de planejamento e licitação do contrato em comento.

Essa insegurança técnica, aliada à imagem negativa do fiscal de contratos na administração, devido a uma cultura histórica brasileira de favorecimento em contratações públicas e desvios realizados por agentes responsáveis, bem como devido ao alto grau de burocracia obrigacional exigida sem uma devida retribuição pecuniária, esvazia o rol de servidores que buscam capacitação para se colocarem à disposição para o exercício dessa tarefa tão importante para a manutenção de um Estado gerencial, longe dos efeitos do patrimonialismo.

Nessa linha intelectiva, Amaral (2010, p. 2) acrescenta a importância que deve ser dada a esta última fase contratual:

Na compra de bens de pronta entrega (contrato de execução imediata), a etapa de execução assume uma relevância menor. Mas na contratação de obras e serviços contínuos, bem como na compra de bens para entrega futura e fabricação de equipamentos sob encomenda, ou seja, nos contratos de duração e de execução diferida, não basta planejar, licitar e celebrar contratos com eficiência: é necessário administrar o contrato, também com eficiência, durante toda sua execução (AMARAL, 2010).

Não obstante, há de se salientar que, por ser essa fase o momento mais ativo em que o fiscal será exigido, este também - por motivos diversos, como: falta de capacitação, escolha randômica para exercício desta função, dentre outros motivos - acaba por cometer erros que comprometem o Estado gerencial, o qual, em essência, busca uma máquina com capacidade de auto melhoramento contínuo e que se preocupe muito mais com a finalidade do que os modelos estatais anteriores se preocupavam. Os vícios trazidos por parte dos Fiscais contratuais em grande ordem se referem à falta de instrumentalidade com os artifícios contratuais corretos em alterações contratuais e sanções administrativas ${ }^{16}$, bem como uma falta de controle no acompanhamento de obrigações fiscais, trabalhistas e previdenciárias e nos prazos contratuais ${ }^{17}$.

\footnotetext{
${ }^{16}$ Verifica-se tais falhas nos acórdãos do TCU: 1.827/2008, 3.289/2011, 963/2010, 6.101/2009, e 361/2007.

${ }^{17}$ Verifica-se tais falhas nos acórdãos do TCU: 964/2012, 2.373/2016, 2.353/2016, 1.674/2014, 1.808/2008 e em REsp 1.241.862/RS - Segunda Turma do STJ.
} 
Visando a uma condução mais segura dos procedimentos nos processos de aquisição da administração pública, essas práticas podem ser amenizadas com ações simples, como a designação de responsável pela execução contratual antes de assinado o contrato (conforme prevê Acórdão no 3.016/2015, do TCU ${ }^{18}$ ), ou até um ostensivo trabalho de construção de uma central de fiscalização contratual, onde constem especialistas em diversas áreas técnicas de atuação (Engenharias, Serviços Terceirizados de mão de obra não especializada, Serviços Terceirizados de mão de obra específica em segurança patrimonial, entre outras) e que esta esteja presente desde a fase de planejamento da contratação, já que, conforme demonstrado, a fase de execução se inicia no planejamento, pois quando planejo mal há fortes indícios que minha execução será deficiente ou, pelo menos, não será normal como seria qualquer outra na qual o planejamento houvesse sido considerado parte essencial.

Todavia, para que haja mudança na forma de operacionalidade da execução contratual e da gestão da contratação pública como um todo, há de se promover um redesenho nas importâncias dadas às fases de planejamento e execução, tendo em vista que o atual sucateamento de ambos os momentos - sob a ótica da exacerbada presença de vícios - se dá pela invalidação de suas grandes importâncias no projeto como um todo.

\section{Considerações finais}

A mudança para o Estado gerencial, a qual, para muitos estudiosos, se apresentou de forma clara com a emenda constitucional de 1998, não se constrói da noite para o dia. É um processo contínuo que ainda se encontra em constante solidificação, já que, conforme demonstrado, um dos grandes desafios para o fiscal de contratos é driblar a prática de formalismos preponderantes sobre as finalidades que o Estado busca alcançar na prestação de determinado serviço à população, de maneira direta ou indireta. Todavia, a preocupação com antigos modelos não se baseia apenas em excessos, mas, também, na ausência de controles de tecnologia da informação, a qual se faz presente nos dias atuais.

\footnotetext{
${ }^{18}$ Trecho do Acórdão: “...recomendação ao (...) para que, relativamente às suas aquisições, implemente controles internos no sentido de que o fiscal do contrato de determinada solução armazene dados da execução contratual, de modo que a equipe de planejamento da contratação encarregada de elaborar os artefatos da próxima licitação da mesma solução ou de solução similar conte com informações de contratos anteriores (séries históricas de contratos de serviços contínuos), o que pode facilitar a definição das quantidades e dos requisitos da nova contratação, semelhantemente ao previsto no art. 67, § 1으, da Lei № 8.666/1993 (item 9.3.3, TC-019.615/2015-9, Acórdão no 3.016/2015-Plenário)."
} 
A tecnologia da informação foi uma grande explosão informacional que cobriu os anos 90 e, logo após o início do século 21, propôs aos controles públicos formas de coibir desvios, como na formação de planilhas de preços de contratos que angariavam milhares de itens. Sem a alternativa da tecnologia, facilitava-se a possibilidade de efetivação de danos ao erário. Portanto, deve ser utilizada de forma contínua nas fiscalizações contratuais, visando a um controle não somente de valores, mas também da temporalidade do contrato e procedimental do mesmo.

Salienta-se, ainda, que mesmo com a utilização de controles corretos no momento da execução contratual, deve haver a preocupação de que nesse momento final o procedimento já foi todo construído e, com isso, o responsável pela fiscalização, além de herdar vícios passados, recebe um processo de aquisição do qual desconhece as minúcias. A fim de promover o saneamento desse vício, o fiscal contratual deverá ser nomeado tão logo evidenciada a necessidade de contratação, a fim de que participe na construção do planejamento para a contratação, coibindo assim qualquer alegação de cometimento de falhas por parte do fiscal por desconhecimento do processo, bem como o auxiliando no momento, quando necessário, de alteração contratual, devido a modificações quantitativas e qualitativas que se fazem necessárias no decorrer do contrato e na necessidade de manutenção do equilíbrio econômico e financeiro.

Esse modelo, além de trazer alterações significativas para a operacionalidade da função do fiscal contratual, trouxe uma mudança visionária no modo pelo qual se percebe a consecução dos fins, já que a proposta do antigo modelo originário de Weber trazia a ideia de que, para o alcance dos fins, fazia-se necessária a proteção exacerbada de procedimentos burocráticos, para que se tornassem mais difíceis os desvios. Todavia, esse formato, além de engessar a máquina pública, com mal resultado na gestão contratos e nos procedimentos, mantinha os favoritismos na administração. Com isso, percebeu-se que não era um modelo que acabaria com os mesmos, mas sim uma contínua busca por melhoramento dos controles e das escolhas individuais as quais se faziam.

Outro ponto também retirado desta pesquisa foi a influência que se tem na escolha equivocada no apontamento de agente responsável pela fiscalização, já que, por não se dar a importância devida a esse papel, é realizada na grande maioria das vezes uma escolha aleatória da pessoa que deve ficar responsável pela execução contratual e, com isso - por incapacidade técnica quanto ao objeto e/ou à fiscalização contratual em si ou por desinteresse - não se obtém o êxito angariado na contratação. Por fim, não se alcança a finalidade pública a ser atendida por aquele procedimento, ferindo de maneira direta o principio da eficiência. Visando solucionar essa problemática, o fiscal deve ser pessoa com especialidade voltada 
à área do objeto, buscar contínua capacitação, bem como a máquina estatal deve buscar formas de recompensar a responsabilidade dessa função.

Esta pesquisa, por se tratar de uma análise generalista quanto ao fiscal de contratos, não se prendeu a assuntos peculiares de cada tipo distinto de fiscalização contratual. Apenas ateve-se a questões gerais de relevância cotidiana nos contratos, não realizou uma análise subjetiva de motivos ensejadores de escolhas peculiares de gestores. Tratou de explicitar a existência de problemas e propor formas de solução. Por consequência, entende-se oportuno sugerir a realização de uma pesquisa voltada à análise da subjetividade das decisões dos gestores públicos responsáveis pelas contratações e as possíveis circunstâncias que influenciam na gestão contratual como um todo, com vistas a propor formas de melhoramento.

Por fim, o que se consolidou com esta pesquisa é que as atribuições do fiscal de contratos ultrapassaram as funções implementadas no formato inicial de fiscalização burocrático-clássico de acompanhamento de execução do objeto e abriu mão para um papel estratégico de prevenção de vícios e de subsidiador de informações tempestivas para a tomada de decisões, por parte do gestor nas contratações. Tal pesquisa também apresentou a importância da tempestividade da tomada de ação do fiscal de contratos dentro das fases do processo de contratação como um todo,assim como identifica o papel ímpar da capacitação e atualização contínua do fiscal em suas competências profissionais.

\section{Referências bibliográficas}

ALMEIDA, Carlos Wellington Leite de. Fiscalização contratual: "Calcanhar de Aquiles" da execução dos contratos administrativos. Brasília: Revista do TCU, p. 53-62, 2009. AMARAL, Antônio Carlos Cintra do. Eficiência nas licitações ou eficácia da contratação? Comentário n172. Disponível em: <www.celc.com.br>

ARAgÃo, Alexandre Santos de. Direito dos serviços públicos. Rio de Janeiro: Forense, 2007.

BARRAL, Daniel Andrade Oliveira. Gestão e Fiscalização de Contratos Administrativos. Brasília, 2016.

BRAGA, Ascenção. A gestão da informação. 1996. Dissertação (Mestrado) Universidade da Beira Interior, Covilhã, Portugal, 1996.

BRASIL. Tribunal de Contas da União. TC 017.825/2009-2. Disponível em: http://www.tcu.gov.br/Consultas/Juris/Docs/ judoc\%5CAcord\%5C20070301\%5CTC-020-559-2004-5.doc.

BRASIL. Tribunal de Contas da União. Acórdão 963/2010. Relator: Benjamin Zymler. Publicado. Disponível em: https://contas.tcu.gov.br/juris/Web/Juris/ ConsultarTextual2/Jurisprudencia.faces. 
BRASIL. Tribunal de Contas da União. Acórdão 3.289/2011. Relator: José Jorge. Publicado. Disponível em: https://contas.tcu.gov.br/juris/Web/Juris/ ConsultarTextual2/Jurisprudencia.faces.

BRASIL. Tribunal de Contas da União. Acórdão 2.714/2015. Relator: Benjamin Zymler. Publicado. Disponível em: https://contas.tcu.gov.br/juris/Web/Juris/ ConsultarTextual2/Jurisprudencia.faces.

Bresser-PereIRA, Luiz Carlos. A Reforma da Administração Pública. São Paulo, 1996 BRESSER-PEREIRA, Luiz Carlos. A Reforma do estado dos anos 90: lógica e mecanismos de controle - Caderno 01. Brasília: Ministério da Administração Federal e Reforma do Estado, p. 10-11, 1997.

Bresser-Pereira, Luiz Carlos. Burocracia Pública e Reforma Gerencial. Brasília: Revista Serviço Público, número comemorativo dos 50 anos. Versão 11 de agosto de 2007.

Carbone, Pedro Paulo; Brandão, Hugo Pena; Leite, João Batista Diniz. Gestão por competências e gestão do conhecimento. Rio de Janeiro: FGV, 2005.

CARVAlho Filho, José dos Santos. Manual de direito administrativo. 9a ed. rev. amp. e atual. Rio de Janeiro: Lumen Juris, 2002.

Chiavenato, Idalberto. Administração nos novos tempos. Rio de Janeiro: Editora Campos, 2000.

Chiavenato, Idalberto. Introdução à Teoria Geral da Administração. 7ạ ed. Rio de Janeiro: Elsevier, - 13a Reimpressão, 2003.

Di PIetro, Maria Sylvia Zanella. Direito administrativo.14ạ ed. São Paulo: Atlas, 2002. MeIRELles, Hely Lopes. Direito administrativo brasileiro. 26ạ ed. São Paulo: Malheiros, 2001.

MEIRELLES, Hely Lopes. Direito administrativo brasileiro. São Paulo: Malheiros, 2002. MENDES, Renato Geraldo. O Processo da contratação pública. Curitiba: Zênite: 2012. OLIVEIRA, Isaac Gezer Silva de. Análise de correspondência aplicada a preposições sobre a eficiência e eficácia do processo de compras públicas a partir da percepção de diferentes atores envolvidos. Rev. Ciênc. Admin., Fortaleza, v. 21, n. 1, p 131-162, jan./jun. 2015.

Seminário de Direito Administrativo, 1., São Paulo, Tribunal de Contas do Município de São Paulo, 2003.

É pós-graduando em Políticas Públicas pela Universidade Federal do Rio de Janeiro (UFRJ). Atualmente é Coordenador de Projetos do Centro de Ciências Jurídicas e Econômicas da UFRJ (CCJE/UFRJ), Administrador da Sede e Fiscal de Contratos Administrativos da Faculdade de Administração e Ciências Contábeis - UFRJ (FACC/UFRJ) e Gerente Operacional do CSPV/UFRJ. Contato: viniciusc_santos@hotmail.com 